\title{
Research on Influencing Factors and Development Strategies of College Students' Health Investment After the COVID-19
}

\author{
Haibo Qiao ${ }^{1, *}$, Bing Zhu ${ }^{2}$ and Yan Peng ${ }^{3}$ \\ ${ }^{1,2}$ School of Economics and Management, Beijing Jiaotong University, Beijing, 100044, China, \\ ${ }^{3}$ School of Management, Capital Normal University, Beijing, 100089, China \\ *Corresponding author. Email: 18120570@bjtu.edu.cn
}

\begin{abstract}
Under the background of Healthy China, the intention of college students' health investment is an important factor that affects the establishment of a good health investment atmosphere in the society. It is also of great significance for providing a full range of health services to enterprises and forming a governance pattern that matches the big health, especially after the COVID-19. Based on the existing research, this paper analyses the health investment intention of college students, using theory of reasoned action and technology acceptance model, which combining health belief models and perceived risks. This is to analyse the influencing factors of health investment from two perspectives: the characteristics of college students and health services. The study found that the health investment of college students is not only directly affected by perceived usefulness, attitudes and subjective norms, but also indirectly affected by perceived ease-of-use and health beliefs; however, perceived risk has no influence on college students' health investment. Accordingly, it provides a reference for schools, enterprises and governments to optimize health investment services and management after the COVID-19.
\end{abstract}

Keywords: COVID-19, Health investment, Theory of reasoned action, Influencing factors, Technology acceptance model.

\section{INTRODUCTION}

At the beginning of 2020, COVID-19 is not only a test for the national health service and governance system, but also a major turning point for people to pay attention to their own health. Some studies have shown that public crisis emergencies are complex, changeable and destructive, which makes individuals in crisis bear huge psychological pressure, easily lead to their physical and psychological imbalance, and even affect their life and work [1]. During the period of staying at home during the COVID-19, the long-term closed environment and the stimulation of the epidemic pressure caused the residents to have negative psychological conditions, and college students, as the high-risk group of psychological problems, have particularly prominent physical and mental health problems [2]. At the same time, more and more college students spontaneously take part in physical exercise at home, which has greatly improved their health awareness and changed their health needs. The development of big health industry has ushered in rare opportunities and challenges.

The National Health Insight Report shows that $90 \%$ of the public have purchased health products, among which health consumption such as online consultations, air purifiers, nutritional supplements, and fitness products has grown rapidly in recent years. Stimulated by the epidemic, young people's perception of health, acceptance of health ideas, desire for health knowledge, and health requirements are relatively high, and the demand for health services has increased sharply, providing new space for the development of the health investment market. Moreover, the strategy of healthy China also provides good policy support for health investment. Up to 2019, The growth rate of health care expenditure of Chinese residents ranked first for the first time, and it has gradually become a key part of national consumption expenditure [3], which has stimulated the maturity of the health consumption market to a large extent. However, in the health investment market of China, health products are an important field, mainly for 
the elderly. Affected by the COVID-19, the types and requirements of college students for health investment have increased, which promotes the development of health market services from single to diversified, provides a good development environment for them.

As a representative of the younger generation, college students not only have a stronger awareness of health crises, but they are also receptive to new things and have a strong consumer influence. They are potential consumers of health investment. Therefore, it is necessary to understand the characteristics and intention of college students' health investment, which not only affect the health of college students, but also help individuals, families and communities to form a good health investment concept, and promote the implementation of the healthy China. Therefore, this article uses the theory of reasoned action and technology acceptance model to explore the factors that affect the intention of health investment. On this basis, the structural equation model is used to explore factors and relationship, aiming to provide satisfactory public services to the government. The key point, which has important theoretical value and practical significance.

\section{RELATED RESEARCH}

At present, many studies have conducted research on the general consumption of college students, such as consumption characteristics of college students, tourism consumption behaviour [4], sports consumption behaviour [5] and cultural consumption behaviour [6]. And research found that it has the characteristics of group character, convenience and price sensitivity, but there is little research on the health investment of college students.

Zhuang Wei clearly divides health consumption into two types from purposes. One refers to medical consumption for the diagnosis and treatment of diseases, maintaining basic physical and mental health, and the other is to prevent diseases and improve physical and mental health [7]. The health consumption referred to in this article mostly refers to the second. Because of its investment characteristics, it is called health investment. Compared with general consumption behaviour, health investment has some particularities. It has certain similarities with medical consumption, and it also has its own uniqueness. Both are healthy consumption, but the former is mostly passive consumption, which is strongly influenced by the objective conditions of the body, while the latter is more initiative. Now, there are few researches on health consumption behaviour in relevant research literature, especially research on health investment, but a considerable amount of literature is research on medical consumption.

As far as medical consumption is concerned, the research content mainly focuses on two aspects. The first is to study the relevant factors of medical consumption, taking the characteristics of the overall consumer group as the entry point, and most of the elderly are the main research objects. They think that medical consumption is mainly related to family income, the proportion of the elderly population, education level etc., and partial research distinguishes urban-rural and regional differences. Hayes et al. took Australian residents as the research object. And they found that the local government will increase investment in education with the improvement of the country's economic level and people's requirements for the quality of education, which is conducive to improving the overall quality of the nation. At the same time, it also makes people pay more attention to their health and are willing to spend more money on medical care [8]. Lightwood studied American residents based on previous models and found that income level, government public health expenditure, and education level all affect medical expenses [9]. Some scholars have used regression models to study the medical consumption of the elderly in rural Jiangsu Province, pointing out that factors such as the personal and family characteristics, economic status, health status, severity of the disease, participation in cooperative medical care, and the quality of medical services of the elderly have an effect [10]. The second is to study the influencing factors of consumers' health consumption behaviour with individual consumers as the entry point, and join the discussion on health behaviour based on sociology and behaviour. Yan Ping analysed the characteristics of tendencies, ability factors and need factors that affect the behaviour of the elderly in seeking medical treatment, and pointed out that medical consumption reflect the health consciousness of the elderly [11]. Liu Shuang summarized the micro-factors in the dynamic process of elderly's consumer behaviour of healthcare products, and showed that consumption consciousness, consumption motivation and consumption ability respectively have a significant influence on consumption amount, consumption frequency and consumption pattern [12]. Deng Min et al. based on the survey data of Nanjing area to study the influence of the medical consumption behaviour and intention of the elderly, and found that the medical consumption intention of the elderly is not only affected by the various social relationships in the social network in which it is located, but also by behavioural beliefs, normative beliefs, behavioural attitudes and subjective norms [13]. Tan Ze found that consumer cognition, product trust, and ability to pay are important influencing factors in studying the consumption of health food by the elderly [14].

In summary, the previous research results related to medical consumption are of great value to health investment research. Most of them reveal the characteristics of medical consumption to a certain 
extent through statistical analysis, but they are limited to the relevance of external factors. analysis. A few literatures on consumer behaviour use the theory of planned behaviour to explore the factors affecting the behaviour of the elderly. The difference lies in the interpretation of the concept and does not comprehensively consider the impact of health beliefs on this behaviour. Health investment is a complex decision-making process, which is affected by many different factors. The general model of health investment should be explored from multiple perspectives such as behavioural science and health concepts. In addition, under the stimulus of the COVID19, health investment research has received more attention, and it should not be limited to the elderly, but should be extended to more and larger groups of people. It also plays a significance role in the Healthy China strategy. Therefore, this research proposes a model of college students' health investment intention with theory of reasoned action and technology acceptance model.

\section{BUILDING MODEL}

Aiming at college students, this article proposes some hypotheses and constructs a model of the factors affecting college students' health investment intention based on the health belief model, theory of reasoned action and technology acceptance model. It also uses questionnaire data to demonstrate its inherent relevance, so as to reveal the influencing factors of health investment, and provide practical suggestions for government management departments and schools after the epidemic.

\subsection{Assumptions about TAM}

Perceived usefulness and perceived ease-of-use are the two core concepts of TAM. The former refers to consumers' perception that health investment can bring material and spiritual benefits, such as improving their physical condition, while the latter refers to how easy it is for consumers to obtain, use, and accept health investment. When consumers perceive health investment can help them prevent diseases and promote health, and the use of products is quick and simple, it will positively affect their behavior intention. At the same time, the convenience of using health investment will also make consumers perceive usefulness.

In addition, because health investment has a certain tendency and consumption threshold, time, economy and other factors of college student make them sensitive to their risks, thereby affecting their intention of health investment. Perceived ease-of-use and perceived usefulness explain the impact on behavioral intention from the perspective of products or services, but ignore the uncertain factors in the consumption process. Therefore, as a supplement to TAM, the perceived risk is added to the TAM model, which refers to the fact that consumers cannot predict the outcome of their consumption and the resulting series of losses in funds and time. When college students believe that health investment will bring about various economic and time losses, their intention of health investment will be weakened.

Based on the above discussion, some hypotheses based on TAM is proposed:

H1: college students' perceived usefulness positively affects health investment intention.

H2: college students' perceived ease-of-use positively affect health investment intention.

H3: college students' perceived ease-of-use positively affects their perceived usefulness.

H4: college students' perceived risks negatively affect health investment intention.

\subsection{Assumptions about TRA}

The intention of college students' health investment is affected by their attitude and subjective norms. Among them, attitude refers to the positive or negative psychological tendency of college students when they conduct health investment. If they believe that healthy products or services can effectively promote their own health, they will have a stronger intention to health investment. Subjective norms refer to how much consumers are affected by their environment when making health investments. If friends of college students are all using similar healthy products or services, they will tend to invest in health due to their comparative psychology.

In addition, health investment is a new type of health-related consumption. College student' own perception of health will be an important factor affecting their attitudes and behaviors. Therefore, the concept of health beliefs is used as the antecedent variable of attitudes to expand the theory of rational behavior. If consumers perceive the benefits of their consumption behavior, they will have a positive psychological tendency, which will affect their intention of health investment. In addition, stronger health beliefs of college students will also promote their intention of health investment.

Based on the above discussion, some hypotheses based on TRA is proposed:

H5: college students' attitude positively affects health investment intention

H6: college students' subjective norms positively affect health investment intention

H7: college students' health beliefs positively affect health investment intention 
H8: Health beliefs positively affect college student' attitudes

Based on the above hypothesis and analysis, this article constructs a model of the influencing factors of college students' health investment intention from TAM and TRA, as shown in figure 1 .

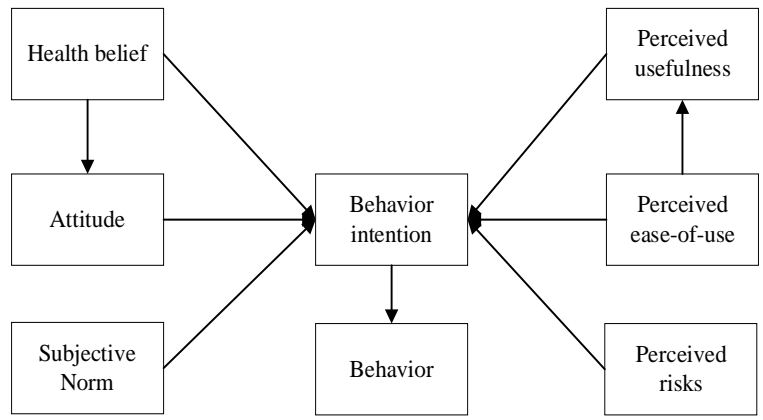

Figure 1. A Model of University Students' Health Investment behaviour intention

\section{APPLICATION RESEARCH}

\subsection{Questionnaire Design}

According to the theoretical model, this article uses a self-made questionnaire to obtain the required data. The questionnaire preparation mainly refers to the scales of Dai Xia, Ajzen, Davis and others in related studies, and the measurement method uses the Likert 5-level scale. The questionnaire is divided into five different scales:

The first is the basic information scale, including gender, age, major, education level, and average monthly living expenses.

The second is the Health Belief Scale, which mainly reflects the individual's concern for their own health and expectations of the outcome of illness from four aspects: the severity and susceptibility of the disease, as well as self-anticipation and response ability. The higher the score, the higher the health belief. A total of 11 items are set.

The third is the rational behavior theory scale, including subjective norms and attitude. Attitude is mainly measured from the two aspects of college students' cognition of new coronary pneumonia, treatment rate, and the positive or negative attitude of adopting relevant anti-epidemic measures to prevent disease. Subjective norm is measured from the perception of social, school, family, friends and other external influences as well as the individual's willingness to comply. A total of 8 items are set.

The fourth is the personal perception scale, which includes three aspects: perceived usefulness, ease-ofuse, and risk. Perceived usefulness is measured from the dimensions of value, benefit, and effectiveness, and perceived ease-of-use is measured from the convenience of using products and services. Perceived risks are mainly measured from economic, time, and physical dimensions, and 11 items are set.

The fifth is the behavioral intention scale, which is mainly measured from two aspects of health investment behavioral intention and recommendation intention, with a total of 3 items.

\subsection{Sample Data Analysis}

This article randomly selects participants from eigth universities across the country by issuing questionnaires online. The questionnaire is issued and collected from February to March 2021. There are a total of 290 questionnaires and 278 valid questionnaires.

In all samples, the proportion of males is $34.53 \%$, and the proportion of females is $65.47 \%$. The gender ratio was unevenly distributed. In terms of academic qualifications, $36.69 \%$ are masters and above, $61.87 \%$ are undergraduates, and $1.44 \%$ are juniors. It is not difficult to find that the proportion of bachelor degree and above is the largest, which is also consistent with expectations. The consumption concepts of this group are relatively new, and the acceptance of health investment may be higher. In terms of monthly living expenses, the subjects in the range of 1000-2000 yuan accounted for $48.92 \%$, followed by subjects in the range of 2000-2500 yuan, which accounted for $23.74 \%$ of the sample number. This is because the subjects' financial resources are mainly Family subsidies, subsidies provided by schools and other additional income, so most of the monthly living standards are less than 2500 yuan. From the above analysis, the survey data of the questionnaire is basically consistent with the actual situation and can be used for follow-up research.

\subsection{Reliability and Validity Test}

The scales in the questionnaires used in this study are all referenced to the mature scales and adapted in accordance with the research content. Therefore, it is believed that the content of the questionnaire is valid and can be analyzed in the next step.

When considering the fit of the model, it is found that normalized factor loading of the question items A6, $\mathrm{A} 11$ and $\mathrm{F} 1$ are less than 0.5 , which makes the model fitting effect poor. Therefore, after excluding the above three question items, use SPSS and Amos to get the results, respectively. The Cronbach $\alpha$ and the standardized factor loads are calculated, and the combined reliability and the average variance extraction are calculated according to formula (1) and formula (2).

$A V E=\left(\sum \lambda^{2}\right) / n$ 


$$
C R=\left(\sum \lambda\right)^{2} /\left(\left(\sum \lambda\right)^{2}+\sum \delta\right)
$$

In the formula, $\lambda$ is the factor loading of the question item, $\delta$ is the corresponding residual variance, and $\mathrm{n}$ is the total number of question items. From this, the results of reliability and validity are obtained, as shown in Table 1. The results show that the value range of Cronbach's $\alpha$ coefficient is $[0.814,0.938]$, and the reliability of the total table is 0.958 . At the same time, the minimum value of the standardized factor loading is 0.674 , which is greater than 0.5 , and the factor loading of $90 \%$ of the question items exceeds 0.7 . The CR is greater than 0.8 , and the AVE is greater than 0.5, indicating that the reliability and convergence validity of the questionnaire are good. In addition, each column value (except the first) shown in Table 2 is less than the first value of its corresponding column, indicating that the questionnaire has better discriminative validity.

Table 1. Reliability and validity results of the questionnaire

\begin{tabular}{|c|c|c|c|c|c|}
\hline variable & item & Normalized factor loading & Cronbach's $\alpha$ & AVE & $\mathrm{CR}$ \\
\hline \multirow{9}{*}{ Health belief } & A1 & 0.687 & \multirow{9}{*}{0.916} & \multirow{9}{*}{0.551} & \multirow{9}{*}{0.917} \\
\hline & A2 & 0.825 & & & \\
\hline & A3 & 0.808 & & & \\
\hline & A4 & 0.73 & & & \\
\hline & A5 & 0.711 & & & \\
\hline & A7 & 0.774 & & & \\
\hline & A8 & 0.709 & & & \\
\hline & A9 & 0.706 & & & \\
\hline & A10 & 0.718 & & & \\
\hline \multirow{3}{*}{ Attitude } & B1 & 0.905 & \multirow{3}{*}{0.934} & \multirow{3}{*}{0.829} & \multirow{3}{*}{0.936} \\
\hline & B2 & 0.936 & & & \\
\hline & B3 & 0.89 & & & \\
\hline \multirow{5}{*}{$\begin{array}{l}\text { Subjective } \\
\text { norms }\end{array}$} & $\mathrm{C} 1$ & 0.875 & \multirow{5}{*}{0.915} & \multirow{5}{*}{0.688} & \multirow{5}{*}{0.916} \\
\hline & $\mathrm{C} 2$ & 0.889 & & & \\
\hline & $\mathrm{C} 3$ & 0.805 & & & \\
\hline & $\mathrm{C} 4$ & 0.847 & & & \\
\hline & $\mathrm{C} 5$ & 0.72 & & & \\
\hline \multirow{3}{*}{$\begin{array}{l}\text { Perceived } \\
\text { usefulness }\end{array}$} & D1 & 0.825 & \multirow{3}{*}{0.925} & \multirow{3}{*}{0.809} & \multirow{3}{*}{0.927} \\
\hline & D2 & 0.931 & & & \\
\hline & D3 & 0.938 & & & \\
\hline \multirow{3}{*}{$\begin{array}{l}\text { Perceived ease- } \\
\text { of-use }\end{array}$} & E1 & 0.816 & \multirow{3}{*}{0.814} & \multirow{3}{*}{0.598} & \multirow{3}{*}{0.817} \\
\hline & E2 & 0.729 & & & \\
\hline & E3 & 0.773 & & & \\
\hline \multirow{4}{*}{ Perceived risk } & F2 & 0.713 & \multirow{4}{*}{0.826} & \multirow{4}{*}{0.558} & \multirow{4}{*}{0.833} \\
\hline & F3 & 0.895 & & & \\
\hline & F4 & 0.684 & & & \\
\hline & F5 & 0.674 & & & \\
\hline \multirow{3}{*}{$\begin{array}{l}\text { Behavior } \\
\text { intention }\end{array}$} & G1 & 0.857 & \multirow{3}{*}{0.863} & \multirow{3}{*}{0.692} & \multirow{3}{*}{0.871} \\
\hline & $\mathrm{G} 2$ & 0.857 & & & \\
\hline & G3 & 0.779 & & & \\
\hline Overall scale & 30 & & 0.958 & & \\
\hline
\end{tabular}

Table 2. Differential validity index

\begin{tabular}{|c|c|c|c|c|c|c|c|}
\hline variable & $\begin{array}{c}\text { Health } \\
\text { belief }\end{array}$ & Attitude & $\begin{array}{c}\text { Subjective } \\
\text { norms }\end{array}$ & $\begin{array}{c}\text { Perceived } \\
\text { usefulness }\end{array}$ & $\begin{array}{c}\text { Perceived } \\
\text { ease-of-use }\end{array}$ & $\begin{array}{c}\text { Perceived } \\
\text { risk }\end{array}$ & $\begin{array}{c}\text { Behavior } \\
\text { intention }\end{array}$ \\
\hline Health belief & 0.742 & & & & & & \\
\hline Attitude & 0.730 & 0.911 & & & & & \\
\hline Subjective norms & 0.506 & 0.764 & 0.829 & & & & \\
\hline Perceived usefulness & 0.634 & 0.806 & 0.790 & 0.899 & & & \\
\hline Perceived ease-of-use & 0.553 & 0.616 & 0.706 & 0.732 & 0.773 & & \\
\hline Perceived risk & 0.608 & 0.483 & 0.361 & 0.391 & 0.540 & 0.747 & \\
\hline Behavior intention & 0.639 & 0.825 & 0.710 & 0.801 & 0.714 & 0.469 & 0.832 \\
\hline
\end{tabular}


Table 3. Parameter estimation results of structural model

\begin{tabular}{|c|c|c|c|c|c|c|}
\hline path & Estimate & Standard error & C.R. & P & $\begin{array}{c}\text { Standardized } \\
\text { estimates }\end{array}$ & result \\
\hline $\begin{array}{c}\text { Health belief } \\
\rightarrow \text { Attitudes }\end{array}$ & 0.512 & 0.05 & 10.171 & $* * *$ & 0.521 & accept \\
\hline $\begin{array}{c}\text { Perceived ease-of-use } \\
\rightarrow \text { Perceived usefulness }\end{array}$ & 0.483 & 0.049 & 9.817 & $* * *$ & 0.508 & accept \\
\hline $\begin{array}{c}\text { Health belief } \\
\rightarrow \text { behavior intention }\end{array}$ & 0.081 & 0.051 & 1.582 & 0.114 & 0.095 & not accept \\
\hline $\begin{array}{c}\text { Attitudes } \\
\rightarrow \text { behavior intention }\end{array}$ & 0.3 & 0.046 & 6.502 & $* * *$ & 0.346 & accept \\
\hline $\begin{array}{c}\text { Subjective norms } \\
\rightarrow \text { behavior intention }\end{array}$ & 0.119 & 0.043 & 2.746 & $* *$ & 0.145 & accept \\
\hline $\begin{array}{c}\text { Perceived ease-of-use } \\
\rightarrow \text { behavior intention }\end{array}$ & 0.05 & 0.044 & 1.146 & 0.252 & 0.068 & not accept \\
\hline $\begin{array}{c}\text { Perceived usefulness } \\
\rightarrow \text { behavior intention }\end{array}$ & 0.239 & 0.041 & 5.829 & $* * *$ & 0.308 & accept \\
\hline $\begin{array}{c}\text { perceived risk } \rightarrow \text { behavior } \\
\text { intention }\end{array}$ & 0.024 & 0.037 & 0.649 & 0.516 & 0.031 & not accept \\
\hline
\end{tabular}

Note: *** means $p<0.001$, ** means $p<0.01$, * means $p<0.05$

\subsection{Structural Model Fitting}

The structural equation model in Amos is used to analyse the test estimation and significance level of the corresponding path. The results are shown in Table 3 . At a significance level of 0.05 , the positive (negative) influence of perceived ease-of-use, perceived risk, and health beliefs on health investment behaviour intentions has not been verified, which means hypotheses $\mathrm{H} 2, \mathrm{H} 4$, and $\mathrm{H} 7$ are not valid. At the significance level of 0.001 , college students' perceived ease-of-use of health investment has a significant role in promoting their perceived usefulness, and perceived usefulness also shows the same result for health investment behaviour intentions, hypotheses $\mathrm{H} 3$ and $\mathrm{H} 1$ are established. At the same level, the hypothesis H8 "health beliefs have a positive effect on college students' attitudes" is established. In addition, at the significance level of 0.01 , assuming that "the positive influence of attitudes and subjective norms on the health investment behaviour intentions of college students" is verified, and it is significant, H5 and H6 are established.

\subsection{Conclusion Discussion}

According to the analysis results, health investment behavior intention is not only directly affected by perceived usefulness, attitude and subjective norms, but also indirectly affected by perceived ease of use and health beliefs; but perceived risk has no influence on college students' health investment behavior intentions.

Health investment behavior intentions firstly depend on the attitude of college students, and the attitude depends on the health beliefs of college students. Strong health beliefs help college students accumulate positive attitudes. During the epidemic, the health beliefs of college students increased significantly. This is not only the awareness of new coronary pneumonia, but also the awareness of other diseases and their own health. This has led college students to be more proactive in investing in health. At the same time, college students have a positive attitude towards COVID-19 prevention measures, which is also an important factor affecting health investment. This similar conclusion also obtained similar results in the medical consumption of the elderly, indicating that attitude is an important factor affecting health consumption. Accordingly, it is possible to consider enhancing the health beliefs of college students to influence the positive attitudes of college students

The health investment behavior intention of college students is affected by their surrounding environment, and the social network of school, family, and friends affect the behavior intention of college students. In conclusion, the influence of relatives is particularly obvious during the epidemic. This is also consistent with the herd mentality and group consumption characteristics of college students. Based on this, we consider improving the environment surrounding college students to promote social pressure on health investment, especially the impact of schools, parents, and friends.

The positive effect of college students' perceived health investment on health can promote behavioral intention. Combining perceived risk and perceived ease of use, college students' health investment is mainly to consider the improvement of their own health, while ignoring various risks in the process, especially 
economic risks and time risks. This is also related to the stable financial resources and weak risk awareness of college students, which also reflects the emphasis on improving health. In addition, although the effect of perceived risk on health investment behavior intentions is not significant, it is not a negative effect originally set, but a positive effect. The reason may be that due to the impact of COVID-19, most college students pay more attention to the improvement of their own health by this consumption behavior; it may also be that health investment is still a relatively new form of consumption. Undergraduates' seeking differences arouse their strong curiosity and interest in health investment, and they are full of positive views on possible benefits. Even in the face of higher risks, they will still have a higher interest in its possible results, which is consistent with the view that high risks are accompanied by high returns in economics. Therefore, in order to improve the health investment behavior intention of college students, we can also start from the perspective of improving the perceived usefulness, and in order to improve the perceived usefulness, we can consider improving the ease of use that can be perceived by college students.

There is no obvious relationship between the health beliefs of college students and their health investment behavior intentions, but indirectly affects their behavior intentions by influencing their attitude changes. After the epidemic, the health beliefs of college students are an important driving force for the development of health investment.

In addition to the health beliefs of college students, the perceived usefulness and ease of use of college students will also have a strong influence on attitudes. Accordingly, the promotion of health investment behavior intention of college students should mainly consider the impact of their attitudes, and can influence their attitudes by influencing college students' perceived usefulness and perceived ease of use.

This research extends the application of rational behavior theory to the field of health investment, and explores the internal relevance combined with the related theories of user perception, effectively explaining the influencing factors of college students' health investment behavior intentions.

\subsection{Research Inspiration}

Combining the results of empirical research, we get the following enlightenment:

First, in order to enhance the health beliefs of college students, strengthen the promotion of healthy living and disease prevention. Studies have shown that the health beliefs of college students are an important factor affecting their attitudes towards health investment. With the effective control of the epidemic, schools have become the main venues for college students. Therefore, it is necessary for the school to advocate a scientific and reasonable life concept to college students, and to cultivate a scientific consumption concept of disease prevention. Through regular publicity activities, publishing articles about health concepts, setting eye-catching words and providing related equipment, etc., college students can subtly cultivate and improve health awareness and concepts while preventing and controlling the epidemic. At the same time, it can be combined with family education and social education. The combination of multiple channels promotes and popularizes healthy content, enhances and consolidates the health awareness of the whole people, and extends the awareness of preventing one's own health.

Second, establish a healthy interactive platform for college students. Since subjective norms have a significant impact on the health investment behaviour intentions of college students, the influence of friends, schools and even social networks can be optimized. In the later stage of the epidemic, many activities of college students were restricted due to restrictions on the scope of activities of college students and the need for epidemic prevention. Therefore, with the school as the core, the health service provider around the school as the unit, and the circle of friends as the link, a healthy interactive platform will be established. On the one hand, the platform provides a fixed place for communication between college students and realizes information sharing. On the other hand, it provides students with a centralized and convenient way of obtaining information and consumption, which meets the requirements of prevention and control in the later stage of the epidemic, and facilitates the acquisition of health services, so that the entire process can be completed in school. Finally, using friendship as a bond can not only achieve a virtuous circle of mutual supervision and mutual influence, thereby promoting the formation of a positive and correct health investment atmosphere among friends, but also providing a good path for the cultivation of health concepts.

Third, provide diverse and convenient health services, especially online services. Studies have shown that the perceived ease of use of health services promotes the perceived usefulness, and can improve the service status from both the school and the supplier. In the later period of epidemic prevention and control, due to the restrictions of the school's epidemic prevention measures, the health behaviour of college students has undergone an important change, from the original form of combining on-campus and off-campus to a form mainly on campus. Therefore, on the one hand, schools can actively provide health investment services, such as providing healthy food in supermarkets and canteens. At the same time, scientific management of equipment makes college students no longer restricted by specific facilities. For example, school sports venues provide 
complete fitness equipment, and measures such as revision of reasonable opening hours and charging rules. On the other hand, off-campus service companies can choose to cooperate with school platforms to transform offline health services into online services, so as to facilitate students to complete at school and help improve consumers' perceived ease of use. It is also possible to appropriately adopt measures such as the refinement of the price range of health consumer services to meet the actual needs of different consumers, thereby expanding the consumer group and increasing the income of health service companies. Appropriate sales strategies or preferential policies can also be formulated to establish a good reputation and product use effects among college students. It also helps to promote college students' positive attitudes toward health investment and stimulate their behavioural intentions.

Fourth, strengthen supervision. Schools can strengthen the monitoring of students' health from multiple angles, and appropriately raise the requirements for physical examinations, so as to indirectly increase the degree of attention of college students to their own health, and form a certain amount of external pressure, thereby enhancing health investment behaviour intentions.

\section{CONCLUSION}

In the context of the normalization of prevention and control, this article combines previous studies to propose a model of the factors affecting college students' health investment and related assumptions, then uses an empirical method to verify the model and assumptions. The research results suggest that we should pay attention to the cultivation of college students' health awareness and healthy habits, and at the same time, use a variety of online and offline service methods to remove location restrictions to meet the needs of college students for health investment after the epidemic. However, this study also has certain limitations. The questionnaire is distributed online, and the target is students from 8 universities, mainly in Beijing, which is geographically strong and cannot explain the overall situation of university students across the country. Follow-up research can continue to expand the sample size, and expand the geographical scope, and launch a more in-depth study of the relevant results.

\section{REFERENCES}

[1] Silva JAMD, Siegmund G, Bredemeier J. Crisis interventions in online psychological counseling [J]. Trends in Psychiatry and Psychotherapy, 2015, 37 (4):171-182.
[2] Jiang Ruichen, Li Anmin. Mental health status and influencing factors of college students in Anhui during the new crown pneumonia epidemic [J]. Environmental and Occupational Medicine, 2020, 37 (09):867-871.

[3] CBN Business Data Center. 2019 China Family Medical and Health Consumption Trend Report [DB/OL]. https://www.docin.com/ p-2176995069.html, 2019.02.

[4] Deng Xinfang. Study on the characteristics of tourism behaviour of college students in Urumqi [D]. Xinjiang Normal University, 2011.

[5] Li Xiaolan. Research on Sportswear Consumption Behaviour of College Students in Xi'an Based on TPB [D].2015.

[6] Maduku, Daniel K. Understanding E-Book Continuance Intention: Empirical Evidence from EBook Users in a Developing Country [J]. Cyberpsychology Behaviour, and Social Networking, 2017, 20(1):30-36.

[7] Zhuang Wei, Gu Xiaofen, Li Yukai. Analysis of the Integrated Development Model of the Health Industry Chain Based on the Demand Side [J]. China Health Economics, 2018, 37(12): 74-76.

[8] Hayes, A. \& A. Chevalier. Education: Association with healthcare expenditure in Australia [J]. Healthy Policy, 2016, 24 (8):152-184.

[9] Lightwood, J. \& A. Glantz. Factors Affecting US Health Care Expenditure: Expert Group Data Estimation [J]. PLOS Medicine, 2016, 13(6):145-191.

[10] Zhang Bing, Wang Yiqiu, Xu Jingting. Research on the Medical Consumption Behaviour of the Rural Elderly in Jiangsu Province-Taking the Rural Areas of Northern Jiangsu as an Example [J]. Journal of Nanjing University of Technology: Social Science Edition, 2008, 7(4):29-34.

[11] Yan Ping. Analysis of Medical Seeking Behaviour of the Elderly in my country [J]. Population and Development, 2008, 14 (6):92-98+85.

[12] Liu Shuang. Study on the consumption behaviour of elderly healthcare products based on crosstheoretical model [D]. Dalian University of Technology, 2018.

[13] Deng Min, Yang Li, Chen Na. Analysis of the influencing factors of the medical consumption behaviour of the elderly under the integration of medical care and nursing-Taking Nanjing as an example[J]. China Health Policy, 2017, 10(01):52-57.

[14] Tan Ze. Investigation and analysis on the consumption behaviour of health food products for the elderly $[\mathrm{J}]$. Oriental Dietary and Health, 2016(11). 